\title{
Research regarding coal-bed wellbore stability based on a discrete element model
}

\author{
Zhu Xiaohua*, Liu Weiji and Jiang Jun \\ School of Mechanical Engineering, Southwest Petroleum University, Chengdu, Sichuan 610500, China \\ (C) China University of Petroleum (Beijing) and Springer-Verlag Berlin Heidelberg 2014
}

\begin{abstract}
Wellbore instability is a key problem restricting efficient production of coal-bed methane. In order to perform thorough and systematic research regarding coal-bed wellbore stability problems, a new discrete element model which fully considers the features of cleat coal-beds is established based on the Kirsch equation. With this model, the safe pipe tripping speed, drilling fluid density window and coalbed collapse/fracture pressure are determined; in addition, the relationships between pipe tripping speed and pipe size, cleat size, etc. and wellbore stability are analyzed in the coal-bed drilling and pipe tripping processes. The case studies show the following results: the wellbore collapses (collapse pressure: 4.33 $\mathrm{MPa}$ ) or fractures (fracture pressure: $12.7 \mathrm{MPa}$ ) in certain directions as a result of swab or surge pressure when the pipe tripping speed is higher than a certain value; the cleat face size has a great influence on wellbore stability, and if the drilling fluid pressure is too low, the wellbore is prone to collapse when the ratio of the face cleat size to butt cleat size is reduced; however, if the drilling fluid pressure is high enough, the butt cleat size has no influence on the wellbore fracture; the factors influencing coal-bed stability include the movement length, pipe size, borehole size.
\end{abstract}

Key words: Coal-bed methane, wellbore stability, discrete element model, pipe tripping; wellbore collapse

\section{Introduction}

Coal-bed methane is an important alternative energy source; its reserves are equal in amount to those of conventional natural gas, but at present the production of coal-bed methane is not very active. The exploration for coalbed methane began in America as early as the 1980s, but until 2010 coal-bed methane production only accounted for approximately $8 \%$ of the total US conventional natural gas production. The coal-bed methane industry in China began relatively late, but its development has been very rapid, as there were more than 5,942 coal-bed methane wells in China by the end of 2011, and the surface coal-bed methane production reached $15.7 \times 10^{8} \mathrm{~m}^{3}$; however, the coal-bed methane production only accounts for approximately $1.6 \%$ of China's total conventional natural gas production (Sani and Ejefodomi, 2011; Shen et al, 2012). The coal beds in China are characterized by low pressure, low permeability, low saturation and strong anisotropy, so horizontal drilling is becoming a favorable choice in coal-bed methane development. The gas producing rates of horizontal wells have reached 10 times those of vertical wells drilled in the same coal seams, with an average being 4-5 times (Matthews, 2005; Shen et al, 2012). However, coal-bed wellbore

*Corresponding author. email: zxhth113@163.com

Received February 23, 2014 stability problems are very significant (especially in multilateral horizontal coal-bed methane wells), due to low tensile strength, low elastic modulus, developed fractures (cleat gaps), strong pressure sensitivity, etc. of coal-beds (Gentzis et al, 2009a; Keim et al, 2011; Huang et al, 2013).

In view of the problems of wellbore stability, many researchers have performed a large number of studies: Zhang et al (2006) studied the effect of the size of horizontal wellbores in coal-beds using the realistic failure process analysis $\left(\mathrm{RFPA}^{2 \mathrm{D}}\right)$. Zhu et al (2007) analyzed the wellbore behavior in fractal formations using the finite element method and poroelastic theories. Whittles et al (2007) described the application of computational modelling to the prediction of the stability of methane drainage boreholes during the extraction life of an active longwall coal panel. Deisman et al (2008) used the Hoek-Brown failure criterion with the geological strength index (GSI) to capture the influence of both cleating and micro-fractures on coal strength. Gentzis (2009b; 2009c) used STABViewTM 2D and 3D to analyze the wellbore instability problems occurring during drilling and production. Deisman et al (2010) and Hawkes (2007) examined wellbore stability based on mechanical properties of the reservoir. Yang and Tian (2011) investigated influential factors on multi-lateral horizontal coal-bed methane wells based on the Hoek-Brown criterion. Qu et al (2010; 2011a; 2011b) did some research on the mechanism of coal-bed wellbore instability and drilling fluid density windows in 
coal-bed methane drilling based on fracture mechanics theory and the 3D discrete element method. Besides, Connell and Jeffrey (2005), Moschovidis et al (2005), Palmer et al (2005a; 2005b), Yan (2005), Dexter (2006), Gentzis and Bolen (2008) examined the effect of seam thickness, seam depth, gas content, permeability, cohesion of the coal, overburden stress, wellbore length, reservoir pressure, drilling fluid density, water rate, mechanical skin and well trajectory on wellbore stability and gas production.

Coal blocks are discontinuous due to the high development of cleats in coal-beds, and the mechanical characteristics of coal blocks are discontinuous and nonlinear. However, the foundation of the current wellbore stability theory is the continuum theory, thus it is impossible to describe the stress strain condition of cleat coal-bed boreholes. As a result, the instability mechanism of wellbores in coal-beds is unclear, and at present a comparatively accurate theoretical model has yet to be developed. In order to perform thorough and systematic research on wellbore stability in coal-beds, a new discrete element model which fully considers the features of cleat coal-beds is established based on the Kirsch equation. With this model, the safe pipe tripping speed, drilling fluid density window and the coal-bed collapse/fracture pressure are determined; in addition, the relationships between pipe tripping speed and pipe size, cleat size, etc. and wellbore stability are analyzed in the processes of coal-bed drilling and pipe tripping.

\section{Establishment of a discrete element model}

There are two approximately perpendicular cleat systems (a butt cleat system and a face cleat system) in a coal-bed, their respective cleat surfaces are located across from each other, dividing the coal-bed into many matrix blocks (Laubach et al, 1998; Yin et al, 2012), as Fig. 1 shows.

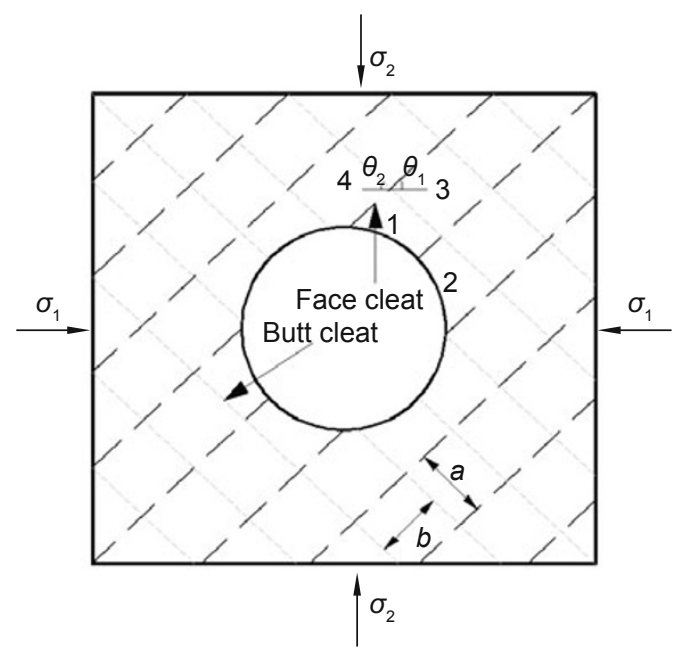

Fig. 1 Cleat system in a coal-bed

As we all know that the wellbore length is much larger than the wellbore diameter. The stress state around the wellbore is plane strain condition in both vertical and horizontal wells (and deviated wells) except for the toe of the wellbore. So, we assume that the plane strain condition on the planes is perpendicular to the wellbore axis, and the plane strain condition can be applied to the vertical and horizontal wells (or deviated wells).

The discrete element method is not only a numerical analysis method, but also a pattern for thinking of rock mechanics. The interaction between each block obeys macroscopic Newton's laws while dividing the coal-bed into many matrix blocks; however, the block itself obeys microscale deformation elastic-plastic mechanics. According to the Kirsch equation, the stress of the matrix block can be expressed as follows:

$$
\left\{\begin{array}{c}
\sigma_{r}=\frac{r_{\mathrm{i}}^{2}}{r^{2}} p_{\mathrm{i}}+\frac{\sigma_{1}+\sigma_{2}}{2}\left(1-\frac{r_{\mathrm{i}}^{2}}{r^{2}}\right)+ \\
\frac{\sigma_{1}-\sigma_{2}}{2}\left(1+\frac{3 r_{\mathrm{i}}^{4}}{r^{4}}-\frac{4 r_{\mathrm{i}}^{2}}{r^{2}}\right) \cos 2 \theta \\
\sigma_{\theta}=-\frac{r_{\mathrm{i}}^{2}}{r^{2}} p_{\mathrm{i}}+\frac{\sigma_{1}+\sigma_{2}}{2}\left(1+\frac{r_{\mathrm{i}}^{2}}{r^{2}}\right)- \\
\frac{\sigma_{1}-\sigma_{2}}{2}\left(1+\frac{3 r_{\mathrm{i}}^{4}}{r^{4}}\right) \cos 2 \theta \\
\tau_{r \theta}=\frac{\sigma_{2}-\sigma_{1}}{2}\left(1+\frac{2 r_{\mathrm{i}}^{2}}{r^{2}}-\frac{3 r_{\mathrm{i}}^{4}}{r^{4}}\right) \sin 2 \theta
\end{array}\right.
$$

where $\sigma_{r}$ is the radial stress; $\sigma_{\theta}$ is the tangential stress; $\tau_{r \theta}$ is the shear stress; $p_{\mathrm{i}}$ is the drilling pressure; $r_{\mathrm{i}}$ is the wellbore radius; $r$ and $\theta$ are the polar coordinates; and $\sigma_{1}$ and $\sigma_{2}$ are the principal stresses.

Converting Eq. (1) from the cylindrical coordinate system to the Cartesian coordinate system, the stress distribution around the wellbore in the Cartesian coordinate system can be expressed as follows:

$$
\left\{\begin{array}{l}
\sigma_{x}=\sigma_{r} \cos ^{2} \theta+\sigma_{\theta} \sin ^{2} \theta-\tau_{r \theta} \sin 2 \theta \\
\sigma_{y}=\sigma_{r} \sin ^{2} \theta+\sigma_{\theta} \cos ^{2} \theta+\tau_{r \theta} \sin 2 \theta \\
\tau_{x y}=\frac{\sigma_{r}-\sigma_{\theta}}{2} \sin 2 \theta+\tau_{r \theta} \cos 2 \theta
\end{array}\right.
$$

Each single coal matrix block is clamped between two cleat faces. When the drilling fluid pressure is not sufficient, the block is more likely to slip along the cleat face, resulting in wellbore collapse; when the drilling fluid pressure is sufficiently high, the tangential stress $\sigma_{\theta}$ which the wellbore rock suffered will turn from compressive to tensile, and if the tangential stress is higher than the tensile strength of the wellbore rock, then the wellbore will undergo tensile failure. Therefore, block one is singled out and analyzed with respect to the stresses, as shown in Fig. 2. The compressive or tensile stress between block two and one (or between four and one) is obtained as follows:

$$
\left\{\begin{array}{l}
\sigma_{21}=\sigma_{y} \cos ^{2} \theta_{1}+\sigma_{x} \sin ^{2} \theta_{1}-\tau_{x y} \sin 2 \theta_{1} \\
\sigma_{41}=\sigma_{y} \cos ^{2} \theta_{1}+\sigma_{x} \sin ^{2} \theta_{1}-\tau_{x y} \sin 2 \theta_{1}
\end{array}\right.
$$

where $\theta_{1}$ is the butt cleat oblique angle. 


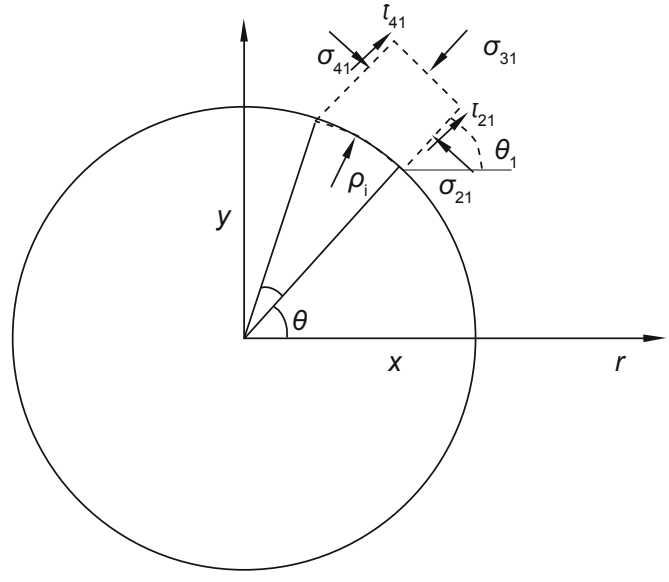

Fig. 2 Stress analysis of a matrix block

According to the research of Osisanya and Schaffitzel (1996), the matrix block size is small (about $10 \mathrm{~mm}$ ). Compared with the borehole size, the matrix block size is much smaller. Thus, the opposite sides of the block can be considered as being equal to each other. The stress value of the acting surface is also considered as the mean stress, such as $\sigma_{41}$ and $\sigma_{21}$. Therefore, the corresponding polar coordinates are as follows:

$$
\begin{aligned}
& \left\{\begin{array}{l}
r_{21}=r_{\mathrm{i}}+b / 2 \\
\theta_{21}=\theta
\end{array}\right. \\
& \left\{\begin{array}{l}
r_{41}=r_{\mathrm{i}}+b / 2 \\
\theta_{41}=\theta+a / r_{\mathrm{i}}
\end{array}\right.
\end{aligned}
$$

The $\sigma_{41}$ and $\sigma_{21}$ can be calculated while substituting Eq. (4) or Eq. (5) into Eq. (1) and Eq. (2).

The critical shear stress when the matric block slips along the cleat face is:

$$
\left\{\begin{array}{l}
\tau_{21}=\tan \varphi_{\mathrm{m}}\left(\sigma_{21}-p_{\mathrm{i}}\right) \\
\tau_{41}=\tan \varphi_{\mathrm{m}}\left(\sigma_{41}-p_{\mathrm{i}}\right)
\end{array}\right.
$$

where $\varphi_{\mathrm{m}}$ is the friction angle of the face cleat.

The compressive stress $\sigma_{31}$ is:

$$
\left\{\begin{array}{l}
\sigma_{31}=\sigma_{y} \cos ^{2} \theta_{2}+\sigma_{x} \sin ^{2} \theta_{2}+\tau_{x y} \sin 2 \theta_{2} \\
r_{31}=r_{\mathrm{i}}+b \\
\theta_{31}=\theta+a / 2 r_{\mathrm{i}}
\end{array}\right.
$$

where $\theta_{2}$ is the face cleat oblique angle.

According to Newton's laws, the critical condition where the matric block does not slip is:

$$
\left(\sigma_{31}-p_{\mathrm{i}}\right) a-\left(\tau_{21}+\tau_{41}+2 C_{\mathrm{m}}\right) b=c \leq a S_{\mathrm{td}}
$$

And the critical condition under which the matric blocks do not undergo tensile failure is:

$$
\min \left[\left(-\sigma_{21}\right),\left(-\sigma_{41}\right)\right]=f \leq S_{\mathrm{td}}
$$

where $b$ is the face cleat size; $a$ is the butt cleat size; $C_{\mathrm{m}}$ is the cohesion of cleats; and $S_{\mathrm{td}}$ is the tensile strength of the cleats.

\section{Pressure fluctuations in wellbores}

Wellbores are very easily broken because they are sensitive to pressure fluctuations caused by tripping out (withdrawing the drill string, negative swab pressures) and tripping in (reinserting the drill string, positive surge pressures) (Lal, 1983; Sorgun and Ozbayoglu, 2010). Therefore, the effect of pressure fluctuations must be considered when studying wellbore stability. The widely used method for calculating pressure fluctuation is the steady state method developed by Burkhardt (Burkhardt, 1961).

$$
\begin{aligned}
& p_{\mathrm{sw}}=\frac{0.196 f \rho_{\mathrm{m}} v^{2} L}{D-d} \\
& v=\left(\frac{d^{2}}{D^{2}-d^{2}}+K_{\mathrm{c}}\right) V
\end{aligned}
$$

where $p_{\mathrm{sw}}$ is the pressure fluctuation, $\mathrm{MPa} ; \rho_{\mathrm{m}}$ is the drilling fluid density, $\mathrm{g} / \mathrm{cm}^{3} ; v$ is the reverse discharging speed of the drilling fluid, $\mathrm{m} / \mathrm{s} ; f$ is the friction factor; $L$ is the pipe length in the wellbore, $\mathrm{m} ; D$ is the diameter of the annulus, $\mathrm{cm}$; $d$ is the pipe outer diameter, $\mathrm{cm} ; K_{\mathrm{c}}$ is the consistency index; and $V$ is the pipe tripping speed, $\mathrm{m} / \mathrm{s}$.

Surge pressure may break down weak formations and lead to wellbore fracture or lost circulation. Swab pressure can cause wellbore collapse or an influx of formation fluids or gas into the borehole, reducing overbalance pressure, thus potentially resulting in a well control situation. The drilling fluid pressure during pipe tripping is as follows:

$$
p_{\mathrm{s}}=p_{\mathrm{i}} \pm p_{\mathrm{sw}}
$$

The drilling fluid pressure has a close relationship with the pipe tripping speed, as shown in Table 1, i.e. the surge and swab pressures will increase when the pipe tripping speed is increased. Therefore, Eq. (1) can also be written as follows:

$$
\left\{\begin{array}{c}
\sigma_{r}=\frac{r_{\mathrm{i}}^{2}}{r^{2}} p_{\mathrm{s}}+\frac{\sigma_{1}+\sigma_{2}}{2}\left(1-\frac{r_{\mathrm{i}}^{2}}{r^{2}}\right)+ \\
\frac{\sigma_{1}-\sigma_{2}}{2}\left(1+\frac{3 r_{\mathrm{i}}^{4}}{r^{4}}-\frac{4 r_{\mathrm{i}}^{2}}{r^{2}}\right) \cos 2 \theta \\
\sigma_{\theta}=-\frac{r_{\mathrm{i}}^{2}}{r^{2}} p_{\mathrm{s}}+\frac{\sigma_{1}+\sigma_{2}}{2}\left(1+\frac{r_{\mathrm{i}}^{2}}{r^{2}}\right)- \\
\frac{\sigma_{1}-\sigma_{2}}{2}\left(1+\frac{3 r_{\mathrm{i}}^{4}}{r^{4}}\right) \cos 2 \theta \\
\tau_{r \theta}=\frac{\sigma_{2}-\sigma_{1}}{2}\left(1+\frac{2 r_{\mathrm{i}}^{2}}{r^{2}}-\frac{3 r_{\mathrm{i}}^{4}}{r^{4}}\right) \sin 2 \theta \\
p_{\mathrm{s}}=p_{\mathrm{i}} \pm p_{\mathrm{sw}}
\end{array}\right.
$$

where $p_{\mathrm{s}}$ is the drilling fluid pressure under the consideration of pressure fluctuation.

\section{Case studies}

In order to clearly show the factors influencing coal-bed 
wellbore stability, the relationships between pipe tripping speed and pipe size, cleat size, etc. and wellbore stability are analyzed based on the above established discrete element model during coal-bed drilling and pipe tripping processes. In the case studies both the face cleat oblique angle and the butt cleat oblique angle are equal to $45^{\circ}$, the other basic calculation parameters are shown in Table 1.

Table 1 Basic calculation parameters

\begin{tabular}{ccccccccccc}
\hline $\begin{array}{c}\sigma_{1} \\
\mathrm{MPa}\end{array}$ & $\begin{array}{c}\sigma_{2} \\
\mathrm{MPa}\end{array}$ & $\begin{array}{c}C_{\mathrm{m}} \\
\mathrm{MPa}\end{array}$ & $\begin{array}{c}a \\
\mathrm{~mm}\end{array}$ & $\begin{array}{c}b \\
\mathrm{~mm}\end{array}$ & $\begin{array}{c}S_{\mathrm{td}} \\
\mathrm{MPa}\end{array}$ & $\begin{array}{c}D \\
\mathrm{~mm}\end{array}$ & $\begin{array}{c}d \\
\mathrm{~mm}\end{array}$ & $\begin{array}{c}\varphi_{\mathrm{m}} \\
\text { degree }\end{array}$ & $\begin{array}{c}L \\
\mathrm{~mm}\end{array}$ & $\begin{array}{c}\rho_{\mathrm{m}} \\
\mathrm{g} / \mathrm{cm}^{3}\end{array}$ \\
\hline 9 & 6 & 1 & 10 & 10 & 1.1 & 215.9 & 152.4 & 10 & 1200 & 1.17 \\
\hline
\end{tabular}

Taking a well of a length of 1,200 $\mathrm{m}$ as an example (vertical length: $600 \mathrm{~m}$, horizontal length: $600 \mathrm{~m}$, length of $152.4 \mathrm{~mm}$ drilling collar: $200 \mathrm{~m}$, length of $127 \mathrm{~mm}$ drill string: 1,000 m). The pressure fluctuations are listed in Table 2.

Table 2 Pressure fluctuations

\begin{tabular}{c|ccccccccc}
\hline Pipe tripping speed $V, \mathrm{~m} / \mathrm{s}$ & 0.5 & 1.0 & 1.5 & 2.0 & 2.5 & 3.0 & 3.5 & 4.0 & 4.5 \\
\hline $\begin{array}{c}\text { Pressure fluctuation } \\
p_{\mathrm{sw}}, \mathrm{MPa}\end{array}$ & 0.55 & 0.91 & 1.34 & 1.77 & 2.67 & 3.60 & 4.72 & 5.69 & 6.80 \\
\hline
\end{tabular}

\subsection{Effect of the pipe tripping speed on wellbore stability and determination of collapse and fracture pressure}

The influence of pipe tripping speed on wellbore stability is very significant, as shown in Fig. 3 . When the tripping out speed is $2.5 \mathrm{~m} / \mathrm{s}\left(p_{\mathrm{s}}=4.33 \mathrm{MPa}\right)$, the swab pressure caused by the pipe movement will lead to wellbore collapse in the $315^{\circ}$ and $135^{\circ}$ directions, therefore, in this case the formation collapse pressure $p_{\mathrm{t}}=p_{\mathrm{s}}=4.33 \mathrm{MPa}$. As shown in Fig. 4 , when the tripping in speed is $4 \mathrm{~m} / \mathrm{s}\left(p_{\mathrm{s}}=12.69 \mathrm{MPa}\right)$, the surge pressure caused by the pipe movement will lead to wellbore fracture in the $0^{\circ}$ and $180^{\circ}$ directions, therefore, in this case

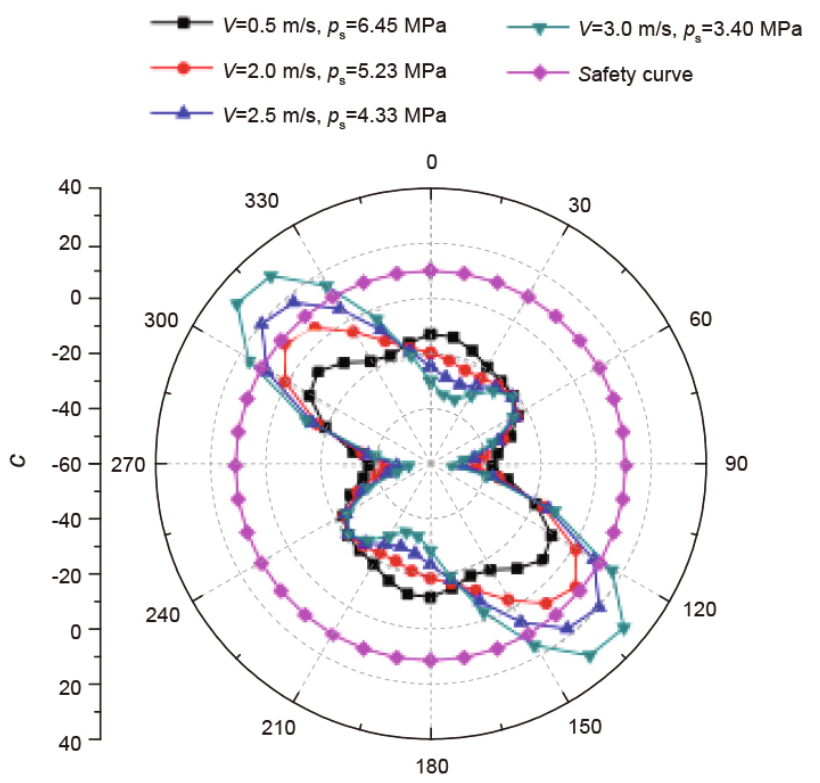

Fig. 3 Effect of the tripping out speed on wellbore stability ( $a=b=10 \mathrm{~mm}$ ) the formation fracture pressure $p_{\mathrm{p}}=p_{\mathrm{s}}=12.69 \mathrm{MPa}$. This signifies that when the drilling fluid pressure ranges from 4.33 $\mathrm{MPa}$ to $12.69 \mathrm{MPa}$ the wellbore is stable; in other words, the corresponding drilling fluid density window is $0.72-1.81$ $\mathrm{g} / \mathrm{cm}^{3}$. Therefore, in order to retain wellbore stability, it is necessary to avoid higher pipe tripping speeds in the pipe tripping process, and to use the security drilling fluid density in the drilling process.

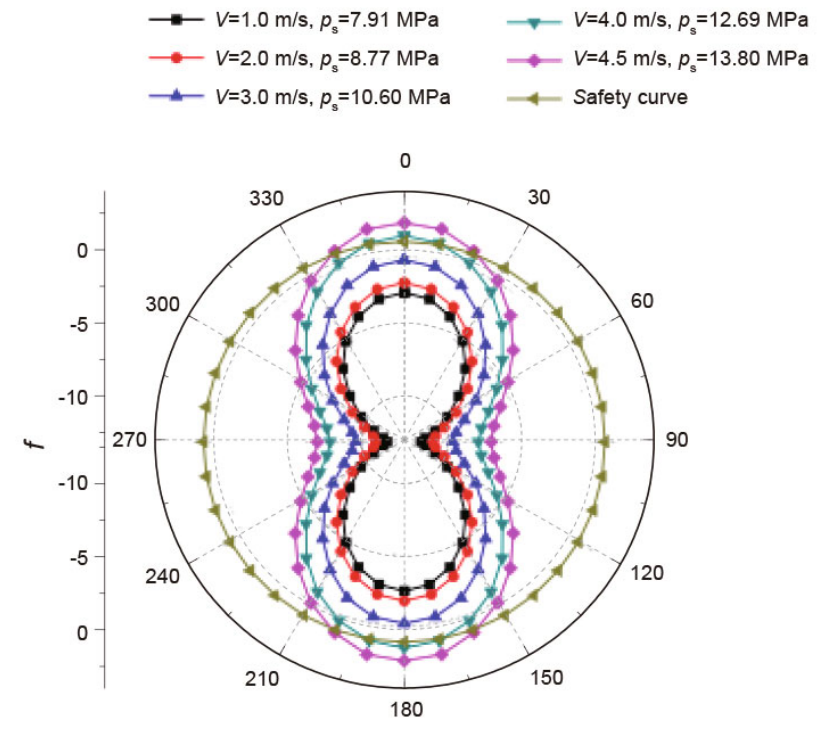

Fig. 4 Effect of the tripping in speed on wellbore stability $(a=b=10 \mathrm{~mm})$

\subsection{Effect of the pipe size on wellbore stability in the pipe tripping process}

From Eqs. (10) and (11) we know that during pipe tripping the factors influencing pressure fluctuation are the drilling fluid properties, annulus diameter, pipe size, pipe tripping speed, etc. The smaller these are, the more stable the wellbore will be. As shown in Fig. 5, the larger the pipe size is, the lower the probability of the wellbore stability will be. Therefore, during pipe tripping, in order to reduce the probability of wellbore instability we should use the smaller sized pipe, while keeping the other influential factors the same.

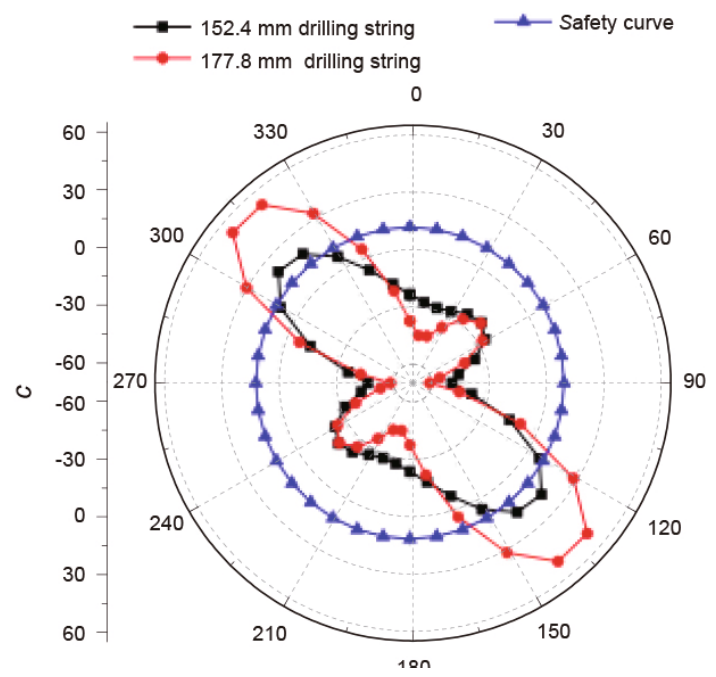

Fig. 5 Effect of the pipe size on wellbore stability $(V=2.5 \mathrm{~m} / \mathrm{s}, a=b=10 \mathrm{~mm})$ 


\subsection{Effect of the cleat size on wellbore stability}

The cleat size affects both wellbore collapse and wellbore fracture. As shown in Fig. 6, when the drilling fluid pressure is sufficiently low, the wellbore will collapse with a decreasing ratio of face cleat size to butt cleat size. The wellbore is in a stable state when $a=b=10 \mathrm{~mm}$, but once $a=2 b=20 \mathrm{~mm}$ the wellbore collapses in the $315^{\circ}$ and $135^{\circ}$ directions. If the drilling fluid pressure is sufficiently high, only the face cleat size has an effect on the wellbore fracture while the butt cleat size does not, as shown in Fig. 7.

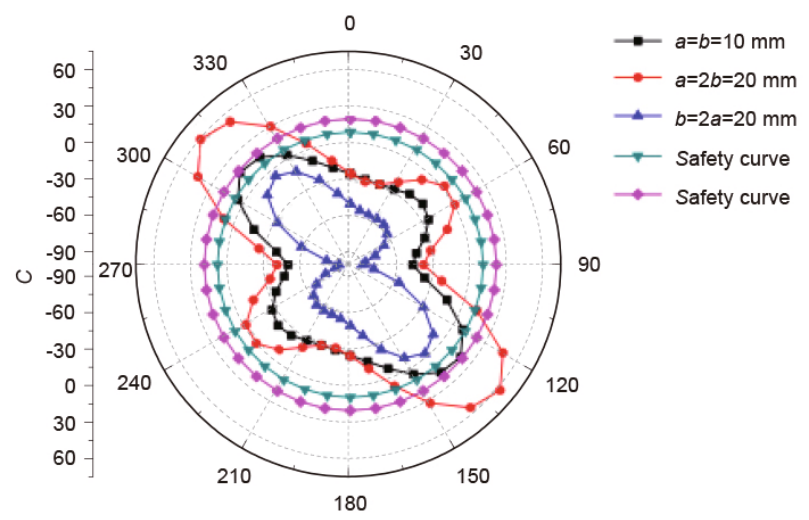

Fig. 6 Effect of the cleat size on wellbore stability when the drilling fluid pressure is too low $\left(p_{\mathrm{i}}=4.33 \mathrm{MPa}\right)$

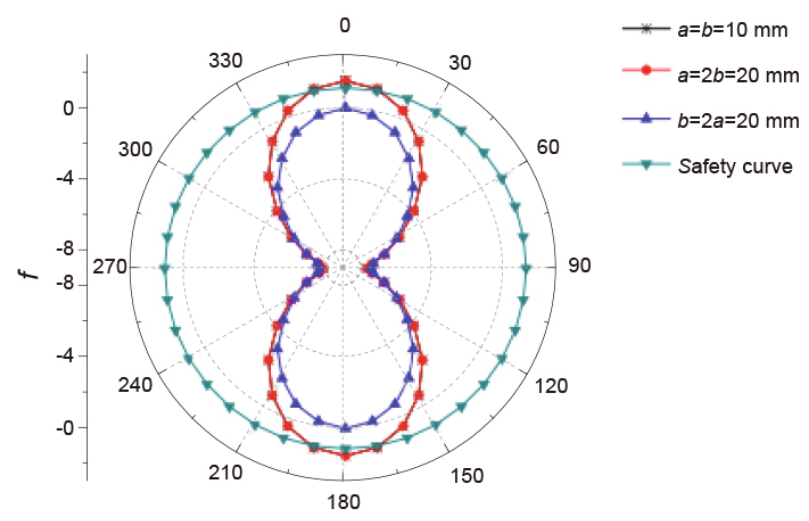

Fig. 7 Effect of the cleat size on wellbore stability when the drilling fluid pressure is too high $\left(p_{\mathrm{i}}=9.67 \mathrm{MPa}\right)$

\subsection{Effect of other factors on wellbore stability}

From Eqs. (8) and (9) and Table 2 we know that, in the processes of coal-bed drilling and pipe tripping, the factors influencing wellbore stability are not only the abovementioned factors, but also the principal stresses, borehole size, pipe movement length, drilling fluid properties, cohesion and tensile strength of cleats, etc. The effect of these factors on wellbore stability can also be investigated using the same method and theoretical model, thus they are not described in this paper.

\section{Conclusions}

In this study, a new discrete element model which fully considers the features of cleat coal-beds is established based on the Kirsch equation. With this model, the safe pipe tripping speed, drilling fluid density window and coal-bed collapse/fracture pressure are determined, and in addition the relationships between pipe tripping speed and pipe size, cleat size, etc. and wellbore stability are analyzed in the processes of drilling coal-bed and pipe tripping. Through the analyses, the following recognitions and conclusions are achieved:

1) With the above established model, the coal-bed collapse/fracture pressure and drilling fluid density window are determined. In this paper, the collapse pressure is shown to be $4.33 \mathrm{MPa}$ and the fracture pressure is $12.69 \mathrm{MPa}$. This signifies that when the drilling fluid pressure is between 4.33 $\mathrm{MPa}$ to $12.69 \mathrm{MPa}$, the wellbore is stable; in other words, the corresponding drilling fluid density window is $0.72-1.81 \mathrm{~g} /$ $\mathrm{cm}^{3}$.

2) Wellbore instability probability increases as the pipe tripping speed increases, and when the pipe tripping speed reaches a certain value the wellbore will collapse or fracture in certain directions. In this paper, when the tripping out speed of the $152.4 \mathrm{~mm}$ drill collar is $2.5 \mathrm{~m} / \mathrm{s}$, the wellbore may collapse in the $315^{\circ}$ and $135^{\circ}$ directions, and when the tripping in speed is $4 \mathrm{~m} / \mathrm{s}$, the wellbore may fracture in the $0^{\circ}$ and $180^{\circ}$ directions.

3 ) In the pipe tripping process, the factors influencing pressure fluctuation are the drilling fluid properties, annulus diameter, pipe size, pipe tripping speed, etc. The smaller the diameter of the annulus, pipe size, pipe tripping speed and drilling fluid density are, the more stable the wellbore will be.

4) When the drilling fluid pressure is sufficiently low, the wellbore will collapse with a decrease in the ratio of the face cleat size to butt cleat size. If the drilling fluid pressure is sufficiently high, only the face cleat size has an effect on the wellbore fracture, while the butt cleat size does not.

\section{References}

Burkhardt J A. Wellbore pressure surges produced by pipe movement. Journal of Petroleum Science and Technology. 1961. 13(6): 595-605

Connell L D and Jeffery R G. History matching for optimization of gas drainage from horizontal wells containing sand propped hydraulic fractures. 2005 International Coalbed Methane Symposium, 16-20 May 2005, Tuscaloosa, Alabama

Deisman N, Gentzis T and Chalaturnyk R J. Unconventional geomechanical testing on coal for coalbed reservoir well design: the Alberta Foothills and Plains. International Journal of Coal Geology. 2008.75(1): 15-26

Deisman N, Ivars D M, Darcel C, et al. Empirical and numerical approaches for geomechanical characterization of coal seam reservoirs. International Journal of Coal Geology. 2010. 82(3-4): 204-212

Dexter D. Investigative CBM modeling for horizontal and other well types. The Conf. Board of Canada Mtg. Calgary, AB. 14-15 February 2006

Gentzis T and Bolen D. The use of numerical simulation in predicting coalbed methane producibility from the Gates coals, Alberta Inner Foothills, Canada: comparison with Mannville coal CBM production in the Alberta Syncline. International Journal of Coal Geology. 2008. 74(3-4): 215-236

Gentzis T, Deisman N and Chalaturnyk R J. Effect of drilling fluids on coal permeability: impact on horizontal wellbore stability. International Journal of Coal Geology. 2009a. 78(3): 177-191 
Gentzis T. Stability analysis of a horizontal coalbed methane well in the Rocky Mountain Front Ranges of southeast British Columbia, Canada. International Journal of Coal Geology. 2009b. 77(3-4): 328337

Gentzis T, Deisman N and Chalaturnyk R J. A method to predict geomechanical properties and model well stability in horizontal boreholes. International Journal of Coal Geology. 2009c. 78(2): 149160

Hawkes C. Assessing the mechanical stability of horizontal boreholes in coal. Canadian Geotechnical Journal. 2007. 44(7): 797-813

Huang W, Qiu Z S, Yang L, et al. Instability mechanism of sidewall and anti-sloughing drilling fluid technique for coalbed methane well drilling. Coal Geology \& Exploration. 2013. 41(2): 37-41

Keim S A, Luxbacher K D and Karmis M. A numerical study of optimization of multilateral horizontal wellbore patterns for coalbed methane production in Southern Shanxi Province, China. International Journal of Coal Geology. 2011. 86(4): 306-317

Lal M. Surge and swab modeling for dynamic pressures and safe trip velocities. IADC/SPE Drilling Conference, 20-23 February 1983, New Orleans, Louisiana (paper SPE 11412)

Laubach S E, Marrett R A, Olson J E, et al. Characteristics and origins of coal cleat: a review. International Journal of Coal Geology. 1998. 35(1): 175-207

Matthews C B. Horizontal drilling the Lower Hartshorne coal, Arkoma Basin, Oklahoma: techniques and results. Circular-Oklahoma Geological Survey Pages 117-122. 2005

Moschovidis Z A, Cameron J R and Palmer I D. Methodology and examples of wellbore stability in coalbed methane wells. 2005 International Coalbed Methane Symposium, 16-20 May, 2005, Tuscaloosa, Alabama

Osisanya S O and Schaffitzel R F. A review of horizontal drilling and completion techniques for recovery of coalbed methane. International Conference on Horizontal Well Technology, 18-20 November 1996, Calgary, Alberta, Canada (paper SPE 37131)

Palmer I D, Cameron J R, Moschovidis Z A, et al. Looking for permeability loss or gain during coalbed methane production. 2005 International Coalbed Methane Symposium, 16-20 May 2005a, Tuscaloosa, Alabama

Palmer I D, Moschovidis Z A, Cameron J R, et al. Coal failure and consequences for coalbed methane wells. SPE Annual Technical Conference and Exhibition, 9-12 October 2005b, Dallas, Texas (paper
SPE 96872)

Qu P and Shen R C. Mechanism of wellbore stability and determination of drilling fluid density window in coalbed methane drilling. Natural Gas Industry. 2010. 30(10): 64-68 (in Chinese)

Qu P, Shen R C and Fu L. Time delay effect due to pore pressure changes and existence of cleats on borehole stability in coal seam. International Journal of Coal Geology. 2011a. 85(2): 212-218

Qu P, Shen R C and Yang H L. Application of the 3D discrete element method in the wellbore stability of coal-bed horizontal wells. Acta Petrolei Sinica. 2011b. 32(1): 153-157 (in Chinese)

Sani A M and Ejefodomi E A. Horizontal wells drilling activity in south Texas unconventional gas resources and microseismic hydraulic fracturing monitoring application to reduce risk and increases the success rate. SPE/DGS Saudi Arabia Section Technical Symposium and Exhibition, 15-18 May 2011, Al-Khobar, Saudi Arabia (paper SPE 149061)

Shen R C, Qiao L and Fu L. Research and application of horizontal drilling for CBM. IADC/SPE Asia Pacific Drilling Technology Conference and Exhibition, 9-11 July 2012, Tianjin, China (paper SPE 155890)

Sorgun M and Ozbayoglu M. Predicting frictional pressure loss during horizontal drilling for non-Newtonian fluids. Energy Sources, Part A. 2010. 33(7): 631-640

Whittles D N, Lowndes I S, Kingman S W, et al. The stability of methane capture boreholes around a longwall coal panel. International Journal of Coal Geology. 2007. 71(2): 313-328

Yan Y L, Qu C T and Zhang N S. Colloidal gas aphrons: a novel approach to preventing formation impairment. Petroleum Science. 2005. 2(2): 82-87

Yang H L and Tian Z L. Wellbore stability analysis of coal seam based on Hoek-Brown criterion. Advanced Materials Research. 2011. 383390: 3882-3888

Yin H, Li Q, Guo L, et al. Evaluation of wellbore stability in coal seams by use of the universal discrete element code method. Natural Gas Industry. 2012. 32(11): 59-63 (in Chinese)

Zhang Z, Tang C N and Li L C. Numerical investigation of wellbore stability during coal bed methane production. China Mining. 2006. 15(9): 56-58 (in Chinese)

Zhu R D, Chen P and Xia H Q. Study of stability of fractured borehole wall. Fault-Block Oil \& Gas Field. 2007. 35(5): 68-71 (in Chinese)

(Edited by Sun Yanhua) 